\title{
PRECEPTORIA: ELO DA INTEGRAÇÃO DOCENTE ASSISTENCIAL - SUPORTE PARA O INTERNATO DE ENFERMAGEM*
}

\author{
Vânia Oliveira Santos ** \\ Maria Virginia Godoy da Silva $* * *$ \\ Lina Márcia Migues Berardinelli ****
}

\begin{abstract}
RESUMO - Este estudo trata sobre PRECEPTORIA, termo este que corresponde às atividades desenvolvidas junto aos alunos pelos enfermeiros assistenciais. Foi analisada em um Hospital Universitário a visão dos enfermeiros sobre as atividades de preceptoria, bem como as dificuldades e facilidades encontradas para executá-las. Constituiu-se alvo deste estudo os enfermeiros responsáveis pelas unidades nas quais se desenvolve o Internato de Enfermagem; modalidade de ensino baseada na Integração Docente Assistencial.
\end{abstract}

ABSTRACT - This study is about PRECEPTORY, term which corresponds to the activity developed next to students by assistencial nurses. In a University Hospital the nurses view about Preceptory activities has been analysed, as well as the difficulties and facilities faced by nurses to execute theses activities. Nuraes who are responsable for units where the Internate in nursing modality of teaching based on assistencial Docent Integration, is developed, were chosen as ain of this study.

\section{INTRODUÇÃO}

A participação dos enfermeiros assistenciais na formação do acadêmico de enfermagem tem sido motivo de discussão entre docentes e profissionais de campo.

Considerando a Integração Docente Assistencial (IDA), como uma proposta para a preparação de pessoal na área de saúde, tomamos como ponto de partida, a necessidade de um aprofundamento acerca das atividades de preceptoria e estratégias que favoreçam a sua operacionalização.

Sabemos que, muitas vezes, docentes e enfermeiros assistenciais têm expectativas diferentes acerca do ensino bem como das atividades a serem desenvolvidas pelo alunado em campo.

Além disto, como a política das duas Instituições (Órgão Formador e Serviço) não é claramente definida, ocorre uma indefinição de papéis, gerando conflitos que vão repercutir no processo ensino aprendizagem.

As divergências têm se acentuado, notadamente, quando se trata do Internato de Enfermagem, modalidade de ensino, desenvolvida com base na Integração Docente Assistencial.

No sentido de minimizar estes conflitos é que as autoridades procuraram estudar o assunto, analisando dados da realidade cotidiana, em consonância com a visão dos especialistas na matéria. Para a análise desta realidade, faz-se necessária uma revisão histórica no Internato de Enfermagem.

\section{Histórico de Internato de Enfermagem}

O distanciamento entre a teoria e a prática do curso de graduação, levou os docentes da Faculdade de Enfermagem da UERJ à reflexões na busca de novos métodos que permitissem ao alunado, uma participação mais efetiva no campo de prática. Deste modo, em 1977, a Direção da Faculdade de Enfermagem propós uma mudança curricular e nesta, imbutiu-se a criação do Internato de Enfermagem.

No processo de mudança curricular foram feitos vários estudos e levantamentos sobre o Internato de Medicina visto que não se dispunha de outro "modelo"; bem como a análise dos conceitos e estratégias sobre "Integração Docente Assistencial" já que esta seria a base que iria alicerçar esta nova modalidade do ensino de Enfermagem.

Em dezembro de 1979 , por iniciativa da Direção da Faculdade de Enfermagem, realizou-se o Seminário sobre "Programação de Atividades Interdisciplinares do estágio Supervisionado" com a participação do corpo docente, representantes discentes e representantes do Hospital Universitário Pedro Ernesto. Neste seminário foram discutidas questões de ordem conceitual, estratégias de implantação e formas de operacionalização.

Em 1980, realizou-se o I Seminário sobre Integração Docente Assistencial com a participação dos docentes e enfermeiros de campo, na tentativa de se estabelecer diretrizes programáticas e como forma de profissionais para incorporar o referido Projeto.

\footnotetext{
* Prêmio Lais Netto dos Reis - 3 Lugar - 42\% Congresso Brasileiro de Enfermagem - Natal-RN

** Professor Assistente do Departamento de Fundamentos de Enfermagem da Faculdade de Enfermagem da UERJ

*** Professor Auxiliar do Departamento de Enfermagem Médico Cirúrgica da Faculdade de Enfermagem da UERJ

**** Enfermeira do Hospital Universitário Pedro Ernesto
} 
Somente em 1982, após várias negociações com o Diretor do Hospital Universitário Pedro Ernesto, instala-se a primeira turma do referido Projeto.

O presente estudo tem, portanto, como objetivos:

- Detectar a visão do enfermeiro sobre o conceito de Preceptor e sobre as suas atribuições.

- Levantar as facilidades e dificuldades encontradas para executar as atividades de Preceptoria.

- Propor estratégias facilitadoras ao desenvolvimento da preceptoria tendo como perspectiva a Integração Docente Assistencial.

Visando a operacionalização deste Projeto foram designados seis professores a fim de desenvolverem suas atividades, integralmente no Hospital. Surgem então as primeiras divergências quanto à forma de conduzí-lo e sobre a sua concepção original.

Os internos embora incorporando a idéia do Internato, levantavam diversas críticas, quanto à carga horária excessiva, falta de tempo para o estudo teórico, método de supervisão e pragmatismo das ações em detrimento do conhecimento teórico.

Desde então, o Internato de Enfermagem no seu processo de desenvolvimento, tem sofrido a modificação de muitas estratégias, tendo sempre como perspectiva o ensino teórico com base na prática.

\section{FUNDAMENTAÇÃO TEÓRICA}

Visando uma compreensão mais clara da Integração Docente Assistencial (IDA), base em que se sustenta o Internato de Enfermagem, as autoras foram buscar nos especialistas embasamento para reflexão sobre o assunto.

De acordo com FILHO ${ }^{5}$ Integração Docente Assistencial ê a união de esforços em um processo crescente de articulação entre Instituições de Serviços e de Saúde, adequados às necessidades reais da população, à produção de conhecimentos e à formação de recursos humanos necessários em determinado contexto da prática de serviços de saúde e de ensino.

PIRES ' 1 , Considera a Integração Docente Assistencial, como uma das estratégias utilizadas pelo Sistema Nacional de Saúde, na busca de melhores níveis de saúde da comunidade, visando evitar a desarticulação existente entre o Ensino e a realidade prática.

COSTA, et alil '2, referem-se à integração como grau de influência recíproca e a participação do enfermeiro, do ensino e do serviço na responsabilidade da assistência com o propósito fundamental do ensino.

Estes autores citando Silva, recomendam o entrosamento eficiente entre enfermeiros/docentes e enfermeiros de serviço, visando a maior adequação entre o ensino e sua aplicação no campo de prática dos alunos".

Observamos que, de acordo com os autores estudados, alguns aspectos de ordem conceitual são comuns, quais sejam:

a) É um processo de articulação entre Instituições de Ensino e de Serviços de Saúde.

b) A influência deve ser ser recíproca e a participação mútua. c) $\mathrm{O}$ entrosamento entre enfermeiros docentes e profissionais de campo, busca a melhoria da prática assistencial e de ensino.

d) Pressupõe-se articulação entre ensino teórico e realidade prática.

\subsection{PRINCÍPIOS QUE NORTEIAM A IDA}

FILHO ${ }^{5}$, recomenda que a IDA se processe efetivamente através de instrumentos formais (convênios, acordos etc) entre as instituições, explicitando seus objetivos e as formas de cooperação entre as entidades envolvidas.

LAGANA ", afirma que a IDA "depende muito da filosofia de trabalho que as Enfermeiras possuem em relação ao que significa Enfermagem". Indica ainda a necessidade da enfermeira de campo participar de todo processo de formação do aluno, contando suas experiências e ajudando-os. Quanto aos docentes, entende que deveriam participar das atividades de campo, assumindo parte da responsabilidade dos serviços prestados.

FILHO ${ }^{5}$, entende que a IDA não se restringe à formação de determinadas categorias profissionais de saúde, mas a todos os níveis de formação de recursos humanos.

Desta forma, depreende-se que a Integração Docente Assistencial é um processo muito abrangente, formal, apoiado em princípios e cuja responsabilidade das instituições envolvidas, deve estar claramente ex plicitada.

MARIA ${ }^{8}$, aponta as divergências entre docentes e Enfermeiros Assistenciais sobre a concepção do papel do Enfermeiro como fator que dificulta a realização da IDA. Enquanto os Docentes esperam que os Enfermeiros sejam educadores e administradores, os Enfermeiros Assistenciais temem que suas tarefas deixem de ser cumpridas e recaiam-lhes críticas.

MINZONI ${ }^{9}$, aponta as seguintes dificuldades para a realização da IDA: a falta de tempo do docente; filosofias diferentes entre Escola e Serviço, onipotência dos docentes e a não valorização da assistência dentro da Universidade.

FERNANDES ${ }^{3}$, relaciona como dificuldades pela presença dos alunos na unidade de trabalho a desordem no serviço e o aumento do fluxo da clíniza. Embora entendam que o Enfermeiro Assistencial possa ajudar na orientação dos alunos, acham necessária a presença do professor ao lado do aluno.

A complexidade do tema exige maior aprofundamento. No entanto, as autoras procuraram apenas traçar alguns obices que interferem diretamente na cıncretização da IDA.

\section{METODOLOGIA}

Para realização deste trabalho utilizou-se ccmo campo de pesquisa o Hospital Universitário Pedro Ernesto (HUPE) que serve de campo de prática aos छ,raduandos da área de saúde da Universidade do Estado do Rio de Janeiro (UERJ) e no qual se vivencia a experiência do Internato de Enfermagem.

Localizado no Município do Rio de Janeir(), o HUPE é uma unidade da UERJ, tèndo como objetivos o ensino, a pesquisa e a prestação de assistencia. É um Hospital de grande porte, dispondo de várias clíricas (geral e especializada), contando hoje com cerca de 
450 leitos, servindo à clientela básicamente de beneficários do INAMPS.

Os dados foram coletados durante os meses de abril e maio de 1989. A coleta foi realizada pelas autoras através de questionário.

$\mathrm{O}$ instrumento constou de 7 (sete) questões abertas e fechadas onde foram levantadas variáveis referentes à conceituação de preceptor, suas atribuições, facilidades e dificuldades para exercer a preceptoria.

A população foi constituida pelos preceptores atualmente lotados como chefes das unidades nas quais se desenvolvem as disciplinas do Internato de Enfermagem do HUPE-UERJ a saber: clínicas médicas, clínicas cirúrgicas, ambulatórios, maternidade, berçários, clínica pediátrica, centro cirúrgico, psiquiatria, unidade intermediária de cirurgia geral.

Foram distribuídos 19 (dezenove) questionários dos quais retornaram 13 (treze).

\section{RESULTADOS E COMENTÁRIOS}

Inicialmente procurou-se levantar a opinião dos entrevistados acerca do conceito de preceptor. Dez enfermeiros correspondendo a $75 \%$ do total, entendem que preceptor é todo enfermeiro que orienta aluno. Esta idéia aparece implicitamente nos conceitos emitidos pelos autores estudados. COSTA et alli ${ }^{2}$, FILHO ${ }^{5}$, e LAGANA ${ }^{7}$, preconizam as enfermeiras de campo participando de todo o processo de formação do aluno, sem qualquer restrição. Entretanto, o regimento do internato restringe a função de preceptor "aos enfermeiros escolhidos nas unidades utilizadas como campo de prática do internato".

Três enfermeiros perfazendo $25 \%$ do total emitem um conceito ainda mais amplo de Preceptoria. Na visão destes entrevistados, preceptor é todo enfermeito que orienta não somente os internos, mas qualquer acadêmico, ou residente de enfermagem.

Aprofundando no conceito de preceptor, buscou-se obter dos entrevistados as opiniões acerca de suas atribuições.

A tabela no 1 apresenta estes dados:

TABELA 1 - Opiniões dos Preceptores acerca das suas atribuições HUPE / UERJ, 1989

\begin{tabular}{|c|c|c|}
\hline ATRIBUIÇŌES & $\mathrm{F}$ & $\%$ \\
\hline Participação na avaliação do aluno; & 11 & 17,5 \\
\hline Orientar o aluno acerca das técnicas básicas, normas e rotinas da unidade; & 10 & 15,9 \\
\hline Supervisionar o aluno na ausência do professor; & 9 & 14,3 \\
\hline Substituição do professor nos seus impedimentos; & 8 & 12,7 \\
\hline Participação nos projetos elaborados pelo professor; & 8 & 12,7 \\
\hline Planejamento, execução e avaliação do programa da disciplina; & 7 & 11,1 \\
\hline Aplicação da prova prático-oral; & 6 & 9,5 \\
\hline realização da "plataforma" da disciplina; & 4 & 6,3 \\
\hline TOTAL & 63 & 100,0 \\
\hline
\end{tabular}

Os dados da tabela $\mathrm{n}$ - 1 revelam que $17,5 \%$ das atribuiçōes percebidas pelos entrevistados, correspondem à participação na avaliação do aluno.

Outras dez atribuições listadas, perfazendo um percentual de $15,9 \%$ do total, estão relacionados à orientação do aluno acerca das técnicas básicas, normas e rotinas da unidade.

A supervisão do aluno na ausência do professor aparece num percentual correspondente a $14,3 \%$ do total.

Dentre os autores estudados, não encontramos delimitadas as atribuições do preceptor ou do docente na política de integração docente assistencial.
LAGANÅ ", defende para "a integração docente - assistencial verdadeira" a participação das enfermeiras de campo em todo o processo de formação do aluno.

MARIA ${ }^{8}$, citando Pignatari reforça que integração siginifica totalidade e complementação, baseada em plane jamento que levará a alcançar os objetivos propostos, encorajando a seqüencialidade do ensino pela prática profissional.

Partindo para a análise da prática da preceptoria, apresentam-se na tabela $n^{\circ} 2$ as facilidades encontradas pelos entrevistados para tal função.

TABELA 2 - Facilidades encontradas pelos entrevistados para o desenvolvimento da Preceptoria HUPE/UERJ, 1989

\begin{tabular}{|c|c|c|}
\hline FACILIDADES & $\mathrm{F}$ & $\%$ \\
\hline Participação no processo ensino-aprendizagem & 11 & 24,4 \\
\hline Gostar de ensinar & 9 & 20,0 \\
\hline Estímulo à reciclagem de procedimentos e/ou conhecimento & 9 & 20,0 \\
\hline Valorização do trabalho do enfermeiro quando na qualidade de Preceptor & 8 & 17,8 \\
\hline Estímulo trazido pelo aluno e/ou professor para reorganizar a unidade & 6 & 13,3 \\
\hline A força de trabalho representada pelo aluno & 2 & 4,5 \\
\hline TOTAL & 45 & 100,0 \\
\hline
\end{tabular}


De acordo com os dados contidos na tabela 2, a participação no processo no ensino aprendizagem aparece com percentual de $24,4 \%$ do total das facilidades apontadas pelos entrevistados.

$\mathrm{O}$ gosto pelo ensino e o estímulo à reciclagem de procedimentos e/ou conhecimentos constituiram-se em percentual de $20,0 \%$ cada.

Estes dados levam as autoras a inferir que a "auto motivação" é elemento facilitador no desempenho das funções da preceptoria.

No entanto, não se pode afirmar que este fato é suficiente para o desempenho satisfatório das referidas funções.

Por outro lado, MARIA ${ }^{8}$, expressa no seu estudo sobre integração Escola-Hospital que o enfermeiro vive pressionado por um volume de tarefas inadiáveis, embotando a sua função de ensino, que não deve ser característica apenas do enfermeiro docente, mas de todo enfermeiro, independente da sua área de atuação.

A tabela 3 apresenta as dificuldades apontadas pelos entrevistados para o desenvolvimento da Preceptoria.

TABELA 3 - Dificuldades encontradas pelos entrevistados para o desenvolvimento da Preceptoria, HUPE/UERJ, 1989

\begin{tabular}{|c|c|c|}
\hline DIFICULDADES & $\mathrm{F}$ & $\%$ \\
\hline Não valorização do trabalho do preceptor & 10 & 31,2 \\
\hline Excesso de atividades como chefe de unidade & 8 & 25,0 \\
\hline Incompatibilidade entre as atividades administrativas e as de ensino por falta de tempo & 5 & 15,6 \\
\hline Excesso de atividades burocráticas & 4 & 12,5 \\
\hline Excesso de pessoal na unidade & 2 & 6,3 \\
\hline Falta de motivação para trabalhar com aluno & 2 & 6,3 \\
\hline Críticas feitas pelo aluno e/ou professor & 1 & 3,1 \\
\hline TOTAL & 32 & 100,0 \\
\hline
\end{tabular}

A não valorização do trabalho do preceptor é apresentada como dificuldade num percentual de $31,2 \%$ correspondendo a dez respondentes. Este dado vem ratificar algumas sugestōes apresentadas pelos entrevistados tais como:

- "que o Preceptor seja remunerado";

- "que haja incentivo em relação à atualização do Preceptor";

- "reconhecimento do cargo/função do Preceptor junto à reitoria";

- "seleção de enfermeiros para função de Preceptor";

Outras dificuldades apontadas pelos Preceptores entrevistados como o excesso de atividades do chefe de unidade $(25,0 \%)$, a incompatibilidade entre as atividades administrativas e as de ensino pela falta de tempo $(15,6 \%)$ confirmam a idéia de MARIA, ao afirmar que os aspectos administrativos absorvem o trabalho do preceptor.

\section{5 - CONCLUSÕES}

Após a análise dos resultados, as autoras chegaram às seguintes conclusões:

Os enfermeiros entendem a função de preceptor conforme a visão dos autores estudados, isto $e$, todo aquele que orienta aluno. No entanto, o Regimento do Internato da Faculdade de Enfermagem da UERJ prevê o exercício da função de preceptor para: “aos enfermeiros escolhidos nas unidades onde se desenvolve o Internato".

A participação no processo ensino aprendizagem é a maior facilidade encontrada para o desenvolvimento da Preceptona.

Entretanto, observa-se que, de acordo com a nossa prática o enfermeiro não opta por exercer a função de preceptor. A escolha recai geralmente em função dos objetivos da disciplina avaliados pelo professor e exigências curriculares.

A principal dificuldade apontada para o desenvolvımento da preceptoria é a não valorização do Preceptor. Este dado reflete o momento atual da relação dos profissionais envolvidos no Internato. Embora o termo "valorização" não esteja claramente definido no questionário, os valores de ordem pessoal, financeiros e as condições de trabalho estão sempre subjacentes nas reuniōes com a preceptoria. Soma-se a isto, o fato de os Preceptores não optarem por exercer a referida. função.

Foram citadas outras dificuldades como o excesso de atividades do chefe da unidade o que caracteriza o momento de difíceis condições de trabalho vivido pelos enfermeiros do hospital de ensino alvo deste estudo.

\section{6 - SUGESTÕES} REM:

Face ao estudo apresentado, as autoras SUGE-

- Promover esforços, no sentido de se institucionalizar o cargo de PRECEPTOR, junto às instâncias da Universidade, campo da pesquisa.

- Estabelecer critérios a partir dos "fatores facilitadores", apontados neste trabalho, para a seleção de Preceptores.

- Propiciar a valorização do Preceptor através de atualização formal.

- Reinvindicar junto às instâncias administrativas da UERJ, incentivo financeiro para os Preceptores selecionados.

- Proceder a reformulação do regimento do Internato de Enfermagem com base nas propostas apresentadas neste estudo. 


\section{REFERÊNCIAS BIBLIOGRÁFICAS}

1 CASTRO, M.M.R. Integração do Ensino e Serviços de Enfermagem com a rede hospitalar governamental. Rev. Bras. Enf., Rio de Janeiro, 28 (3): 28-36, 1975.

2 COS TA, L.A.T. et alii. Integração Ensino e Serviço. Estudo Preliminar da UnB. Rev. Bras. Enf. Brasflia, 31 (8): 222-36, 1978.

3 FERNANDES, L.L. LEITE, M.L. integração do Ensino com a Assistência na Enfermagem: Uma Prioridade para o campo clínico. Rev. Bras. Enf., Brasflia, 34 (5): 164-74, 1981.

4 FEUERJ - Regimento Interno do Internato de Enfermagem. Rio de Janeiro, 1988.

5 FILHO, G.R.C. Programa de Integragāo Docente Assistencial. Cadernos de Ciências da Saúde. no 3. MEC/SESU/CCS, 1981.

6 KURCGANT, P. CIAMPONE, M.H.T. Um ponto de refelexão sobre a integração, docente-assistencial na enfermagem. Enfoque, São Paulo, 15 (3): 62-3, 1987.
7 LAGANÅ, M. T.C. Integração: docente-assistencial. Enfoque, São Paulo, 14 (1): 12-5, 1986.

8 MARIA, V.L.R. Integração Escola - Hospital. Enfermagem Moderna, Rio de Janeiro, 2 (1): 25-8, 1984.

9 MINZONI, M.A. Alguns aspectos da integração docenteassistencial. Rev. Bras. Enf., São Paulo, 3 (4): 137-39, 1983.

10 NE TO, E.R. Integração Docente Assistencial - Suas Estratégias, Origens e Implicaçóes e Perspectivas. São Paulo, 1979 (Dissertação de mestrado).

11 PIRES, L.S. et alii. Importância da Integraçằo Docente Assistencial: Uma tentativa realizada em um hospital militar -Rev.Bras.Enf., Braślia, 35 (9): 95-101, 1982.

12 RIBEIRO, C.M. A gestão Administrativa da Enfermagem Integral nos Serviços de Saúde. Rev. Bras. Enf., Rio de Janeiro, 24 : 70-100,1971.

13 TORRES, I.M.O. et alii. Internato de Enfermagem e Nutrição - Uma modalidade de integração Docente Assistencial. Rev. Bras. Enf., Brasilia, 37 (3/4): 289-89, 1984.

\section{ANEXOS \\ ANEXO I - INSTRUMENTO DE COLETA DE DADOS}

Assinale com um $\mathrm{X}$ as afirmativas que você considerar corretas:

1) - Na sua opinião "Preceptor" 6 :

( ) todo "Enfermeiro Chefe de Unidade"

( ) todo Enfermeiro que orienta aluno, em um hospital de ensino

( ) apenas o "Enfermeiro Chefe de Unidade", cu ja clínica é utilizada como "campo de prática"

( ) qualquer Enfermeiro, desde que designado para chefia do serviço

( ) nenhuma das respostas acima

( ) outra definição

2 - São atribuiçōes do "Preceptor":

( ) orientar o aluno acerca das técnicas básicas, normas e rotinas da unidade

( ) realizar a "plataforma da disciplina"

( ) planejar, executar e avaliar o programa da disciplina

( ) aplicar prova prático-oral

( ) substituir o professor nos seus impedimentos

( ) participar na avaliação do aluno

( ) participar nos projetos elaborados pelo professor

( ) supervisionar o aluno na ausência do professor

- Sâo facilidades encontradas por você para o desenvolvimento da "Preceptoria":

( ) gostar de ensinar

( ) estímulo trazido pelo aluno e/ou professor para reorganizar a unidade

( ) participação no processo ensino-aprendizagem

( ) estímulo à reciclagem de procedimentos e/ou conhecimentos

( ) valorização do trabalho do enfermeiro quando na qualidade de Preceptor

( ) a força de trabalho representada pelo aluno

( ) a força de trabalho representada pelo professor

4 - Das finalidades acima relacionadas, cite a que mais interfere no desempenho da sua função de Preceptor. Justifique. 
5 - São dificuldades encontradas por você para exercer a "Preceptoria":

( ) excesso de atividades, como chefe de unidade não permitindo o acompanhamento do aluno

( ) o excesso de pessoal na unidade

( ) excesso de "atividades burocráticas" a serem realizadas

( ) o aluno é muito "cansativo"

( ) as críticas feitas pelo aluno e/ou professor

( ) a não valorização do trabalho do "Preceptor"

( ) não me sinto motivada para trabalhar com o aluno

( ) incompatibilidade entre as atividades administrativas e as de ensino por falta de tempo

6 - Das dificuldades acima relacionadas, cite a que mais infere no desempenho da sua função de Preceptor. Justifique.

7 - Apresente sugestões para que o Enfermeiro possa desempenhar sua função de Preceptor com maior satisfação

ANEXO II

Sugestões apresentadas pelos Preceptores:

1) Que o Preceptor seja remunerado

- Que tenhamos direito a férias como o professor

- Que haja maior incentivo em relação à nossa atualização

2) Reconhecimento do cargo/função do preceptor .

- Formação de grupo específico para tal função (para área específica: médica, cirúrgica, pediátrica etc)

- Capacitação dos enfermeiros para que exerçam atividades didáticas, práticas etc, através de cursos de reciclagem e extensão

3) Que seja somente preceptor

- Que seja reconhecido junto à Reitoria a função do enfermeiro como "Auxiliar de ensino"

4) Valorização técnica e remunerada do trabalho de preceptoria

- Melhor distribuição da carga horária do aluno

- Enfatizar as responsabilidades do aluno

- Participação do preceptor em reciclagem

- Participação do preceptor no planejamento das atividades do aluno

- Trabalho em equipe do Professor e Preceptor

5) O enfermeiro tinha que ser estimulado a se especializar por área

- Ter consciência de que o enfermeiro é um Preceptor

6) Seleção enfermeiros para a função de preceptor a partir do desejo próprio (dos mesmos).

- A unidade selecionada para campo de prática deveria ter um quantitativo de funcionários maior para que o enfermeiro pudesse exercer a preceptoria. $\mathrm{O}$ que ocorre na prática hoje são profissionais "tarefeiros" correndo dentro da enfermaria.
- O preceptor deveria ter 45 dias de férias, remuneração diferenciada, liberação total para cursos e eventos.

7) igualdade de condições preceptor/professor

- valorização do trabalho do preceptor pela faculdade

8) Em branco

9) Fazer reciclagem

- Deveria ser reconhecido como Auxiliar de ensino e receber como tal, pois na realidade o preceptor, além de ter que dar conta das suas atividades na unidade, tem também que ensinar e muitas vezes ainda se sujeitar a ser avaliado pelo aluno do internato ou residente

10) Colocação de enfermeiros lideres de equipe

- Liberação dos preceptores para treinamento

- Cursos de atualização junto a FEUERJ

11) Melhoria das condições de trabalho

- Aumento do pessoal de enfermagem como por exemplo enfermeiro nas 24 horas

12) Valorização do trabalho do enfermeiro como preceptor

- Substituição pelo professor nos impedimentos do enfermeiro e vice-versa

- Que o professor permanecesse na unidade por mais tempo

- Comunicação em caso de ausência do professor a preceptoria, pois muitas vezes o aluno não informa bem ou necessita ajuda do professor

- Melhor entrosamento entre professor e preceptor: trabalho mútuo

- Afixar escala do aluno pois o mesmo ausenta-se por longo tempo: atividades extras, reuniões, etc.

- remuneração de acordo com o professor auxiliar 